\title{
Metodologia para deteç̧ão de infecções latentes de Monilinia fructicola em frutas de caroço
}

\author{
Methodology for the detection of latent infections of Monilinia fructicola in stone fruits
}

\author{
Luciene Martins Moreira $^{{ }^{*}}$ Louise Larissa May-De Mio ${ }^{\mathrm{I}}$
}

\section{RESUMO}

O fungo Monilinia fructicola, causador da podridão parda, é o patógeno mais importante economicamente para as fruteiras de caroço. O fungo infecta desde a fase de floração, podendo ficar latente nos frutos $e$ manifestar sintomas durante a colheita e pós-colheita. $O$ presente trabalho objetivou avaliar metodologias para detectar infecções latentes em frutos em desenvolvimento para diferentes cultivares de fruteiras de caroço. Foram escolhidas oito cultivares de fruteiras de caroço para avaliar infecções latentes de M. fructicola. Para tanto, coletaram-se 30 frutos de cada cultivar, separando-os em dois lotes de 15 frutos, sendo um deles submetido à imersão, por dois minutos, em solução de etanol $70 \%$, posteriormente em hipoclorito de sódio $2 \%, e$ finalmente lavados em água esterilizada. O tratamento para o segundo lote de frutos foi semelhante ao anterior, acrescido de solução de paraquat $2 \%$ (paraquat - $200 \mathrm{~g} \mathrm{~L}^{-1}$, Gramocil- SC) após o hipoclorito. Após os tratamentos, os frutos foram postos em câmara úmida em embalagens plásticas contendo papel de filtro umedecido, à temperatura ambiente. A avaliação da incidência da doença foi feita a cada 48 horas por um período de 10 dias. As infecções latentes foram detectadas na maioria das cultivares avaliadas com os dois métodos, sendo que, nos frutos próximo à maturação, estas surgiram com maior freqüência. O tratamento em que se usou o herbicida aumentou a detecção da podridão parda nas cultivares de ameixa Reubennel e Harry Pickstone. Para os pêssegos, na cultivar "BR-3", os dois métodos favoreceram a detecção, porém, nas cultivares "Chimarrita" e "Vila Nova", quando não se utilizou o paraquat, houve maior detecção das infecções latentes.

Palavras-chave: podridão parda, latência, pêssego, ameixa.

\section{ABSTRACT}

The brown rot fungus Monilinia fructicola is economically the most important pathogen for stone fruit trees. The fungus infects since blossoming and may remain latent in the fruits and manifest symptoms during harvest and postharvest. The present study aimed at evaluating methodologies to detect latent infections in developing fruits for different cultivars of stone fruit trees. Eight cultivars of stone fruit trees were chosen in order to evaluate latent infections of M. fructicola. For that purpose, 30 fruits of each cultivar were collected and separated into two batches of 15 fruits. One of them was subject to immersion for two minutes in a sequence of ethanol solution $70 \%$, later, sodium hypochlorite $2 \%$, and finally washed in sterilized water. The treatment for the second batch of fruits was similar to the first one, adding paraquat solution 2\% (paraquat - $200 \mathrm{~g} \mathrm{~L} \mathrm{~L}^{-1}$, Gramocil-SC) after the hypochlorite. After the treatments, the fruits were laid in humid chamber in plastic packages containing humid filter paper at room temperature. The evaluation of the incidence of the disease was carried out every 48 hours for 10 days. The latent infections were detected in the majority of the cultivars evaluated with the two methods, mainly in the fruits closer to maturation. The treatment in which herbicide was used increased the detection of brown rot in the plum cultivars Reubennel and Harry Pickstone. For the peaches in cultivar BR-3, the two methods favored the detection; however, in the cultivars Chimarrita and Vila Nova there was higher detection of latent infection when paraquat was not utilized.

Key words: brown rot, latency, peach, plum.

\section{INTRODUÇÃO}

O fungo Monilinia fructicola, causador da podridão parda, é o patógeno mais importante economicamente entre os causadores de doenças nas fruteiras de caroço. As perdas na produção resultam da infecção das flores e do apodrecimento dos frutos nas fases de colheita e pós-colheita. Além disso, os

'Departamento de Fitotecnia e Fitossanitarismo, Universidade Federal do Paraná (UFPR). Rua dos Funcionários, 1540, 80035050, Curitiba, PR, Brasil. E-mail: lmmoreira@terra.com.br. *Autor para correpondência. 
cancros de ramos formados a partir das flores infectadas servem como fonte de inóculo tanto para frutos maduros, como para os imaturos (EMERY et al., 2000).

São raros os relatos de resistência de cultivares quanto a essa doença, sendo a epidemia influenciada pela quantidade de inóculo na área, pela época de colheita da cultivar e pelas condições climáticas favoráveis.

As infecções latentes nos frutos imaturos, normalmente, vêm de flores que sobrevivem à infecção, mas originam frutos contendo o patógeno (MAY-DE MIO et al., 2004). As informações sobre a capacidade de o patógeno infectar durante o desenvolvimento dos frutos são escassas; porém, há relatos, para pessegueiro, de que o fungo pode penetrar pelos estômatos, quando os frutos estão imaturos, e na região da inserção do pêlo, no caso de frutos maduros (BYRDE \& WILLETTS, 1977). Segundo tais autores, a penetração direta pela cutícula também pode ocorrer, porém em baixa freqüência. O que realmente favorece a infecção é a ocorrência de ferimentos, mesmo nos estágios iniciais de desenvolvimento dos frutos, tais como os ocasionados por granizo e insetos. Além disso, condições climáticas favoráveis, próximas ao período de colheita, favorecem o desenvolvimento do patógeno (MOREIRA, 2005).

Vários autores têm dado ênfase ao estudo de infecções latentes em culturas como damasco, ameixa, cereja e pêssego (WADE \& CRUICKSHANK, 1992; NORTHOVER \& CERKAUSKAS, 1994; WITTIG et al., 1997; EMERY et al., 2000). A detecção dessas infecções é importante, visto que estas irão se expressar nos frutos durante a maturação, na colheita, estocagem e comercialização (ADASKAVEG et al., 2000). Alguns pesquisadores estudaram meios para detectar infecções latentes precocemente em outros países como Canadá e Estados Unidos (NORTHOVER \& CERKAUSKAS 1994; ADASKAVEG et al., 2000; EMERY et al., 2000), com o intuito de auxiliar na correção ou adequação do programa de manejo adotado, diminuindo assim os riscos de uma epidemia em précolheita. Considerando-se que no Brasil não há estudos disponíveis sobre infecções latentes nas fruteiras de caroço, nem mesmo sobre mecanismos para detectá-las, o presente trabalho teve como objetivos detectar infecções latentes em diferentes cultivares de fruteiras de caroço e comparar dois métodos distintos para o monitoramento destas infecções, desde o início do desenvolvimento até a pré-maturação em pomar comercial da Lapa - Paraná.

\section{MATERIAL E MÉTODOS}

Com intuito de monitorar as infecções latentes em frutos em desenvolvimento, foram selecionadas oito cultivares entre pêssegos, ameixas e nectarina. As cultivares de pêssego foram: "Vila Nova" (ciclo tardio), “Chimarrita” (ciclo médio), “BR-3” e "Premier” (ciclo precoce). As de ameixa foram: “Amarelinha”, "Reubennel” e "Harry Pickstone” (HP), (ciclo tardio) e apenas uma de nectarina, cultivar "Sunred" (ciclo precoce). As diferenças entre as cultivares em relação à maturação foram citadas por BIASI et al. (2004).

O pomar comercial com as cultivares mencionadas está localizado no município da Lapa $\mathrm{PR}$, conduzido sob sistema de taça, com plantas espaçadas em seis metros entre linhas e em três metros na linha, sendo que, na ocasião do experimento, as plantas estavam com idade média de seis anos.

Os tratamentos fitossanitários para manejo da doença foram à base dos ingredientes ativos benomyl, mancozeb, iprodione e captan, sendo os dois primeiros aplicados na floração e os demais usados em alternância, aplicados em pré-colheita. Foram realizadas quatro coletas de 30 frutos de cada cultivar, que eram acondicionados em sacos de papel e encaminhados ao Laboratório de Fitopatologia da Universidade Federal do Paraná. Os frutos foram divididos em dois lotes de 15 frutos, sendo o primeiro imerso, por dois minutos, em solução de etanol $70 \%$, posteriormente em hipoclorito de sódio 2\%, e finalmente lavados em água esterilizada. O segundo lote foi semelhante ao anterior, acrescido de solução de paraquat 2\% (paraquat - 200g $\mathrm{L}^{-1}$, Gramocil-SC) após o hipoclorito. Em seguida, foram postos em câmara úmida em embalagens plásticas contendo papel de filtro umedecido, deixados no ambiente do laboratório. A avaliação da incidência da doença foi feita a cada 48 horas, por um período de dez dias. Neste período, os frutos infectados internamente pelo patógeno expressavam esporulação abundante e típica da doença e nitidamente distinguível das demais infecções fúngicas.

Os dados de infecção nos frutos foram transformados em porcentagem de incidência média em relação aos 30 frutos por variedade ao longo das quatro datas de coletas. Para uma análise qualitativa e comparativa entre os testes de detecção da infecção latente, entre as cultivares analisadas e as diferentes datas de coleta, os dados foram apresentados em gráficos do tipo Box Plot do programa STATISTICA ${ }^{\circledR}$ versão 6.0 .

Ciência Rural, v.37, n.3, mai-jun, 2007. 


\section{RESULTADOS E DISCUSSÃO}

Os resultados obtidos evidenciaram a existência de infecções latentes na maioria das cultivares avaliadas, com os dois métodos utilizados (Tabela 1). A deteç̧ão das infecções não apresentou regularidade entre as coletas, podendo ter relação com o período de aplicação dos fungicidas e a freqüência de chuvas (Figura 1). A temperatura no mês de outubro foi menor em relação a novembro e, a partir deste último mês, observou-se um aumento gradativo da temperatura para a faixa ideal do patógeno $\left(+/-25^{\circ} \mathrm{C}\right)$, estando ótima já no início de dezembro (Figura 1), quando há maior quantidade de inóculo na área devido ao amadurecimento de algumas cultivares e melhores condições climáticas para o fungo esporular e disseminar. Com as informações obtidas, pode-se constatar que em um pomar misto as cultivares precoces poderão favorecer a sobrevivência do patógeno no local.

Diversos autores relataram que a proximidade da fase de amadurecimento de frutos favorece a expressão das infecções latentes, as quais podem surgir também durante a pós-colheita ou a senescência (CRUICKSHANK \& WADE, 1992; LUO et al., 2001; MARI et al., 2003; LUO \& MICHAILIDES, 2003). Esta ocorrência pode ser observada, com exceção da cultivar "Vila Nova", durante as avaliações para as diferentes cultivares monitoradas, onde os sintomas eram prevalentes à medida em que os frutos aproximavam-se da maturação (Tabela 1e Figura 2b).

Das cultivares de ameixas avaliadas, a "Reubennel" apresentou infecções latentes em todas as quatro épocas de amostragem, especialmente quando os frutos foram tratados com etanol + hipoclorito + paraquat (Tabela 1). Com este mesmo tratamento, a cultivar de ameixa "Amarelinha" não mostrou infecções e a "Harry Pickstone" (HP) apresentou incidência de infecções latentes principalmente nos frutos da última coleta. Para o tratamento etanol + hipoclorito, não foram detectadas tais infecções (Tabela 1).

Na figura 2, estão os "Box plots", ou diagramas de caixa, que são excelentes ferramentas para expressar informações variadas de banco de dados, principalmente para ilustrar a variabilidade entre diferentes grupos de dados ou mesmo "outliers" (erros). Isso fornece uma resumida visão de muitos aspectos da distribuição, demonstrando descritivamente o comportamento da variável resposta, proporção da incidência da doença para os fatores data, método de avaliação da infeç̧ão latente e cultivares, em que se pode destacar nítida diferença na terceira data de coleta (Figura 2b) e diferenças entre as cultivares (Figura 2 c) e os métodos (Figura 2a).

Para as cultivares de pêssego, na "BR-3" e na "Chimarrita", o paraquat auxiliou na manifestação das infecções latentes, mesmo os frutos estando na fase de maturação. Com o tratamento etanol + hipoclorito, os frutos das cultivares de pessegueiro "BR-3" e "Chimarrita" manifestaram elevada incidência de infecções, e a cultivar "Vila Nova" apresentou uma menor podridão de frutos (Tabela 1 e Figura 2c). A figura 2c mostra que a maior freqüência de observações de infecções latentes foi na ameixa "Reubennel" e no pêssego "BR-3".

O paraquat usado neste trabalho teve a finalidade de induzir a senescência do tecido e estimular a colonização do fruto pelo fungo, desde os estágios mais precoces de desenvolvimento. Na figura 2a,

Tabela 1 - Monitoramento de infecções latentes de Monilinia fructicola em diferentes cultivares de frutas de caroço tratadas com etanol $70 \%$, hipoclorito $2 \%$ e com ou sem paraquat $2 \%$, em quatro datas de coleta.

\begin{tabular}{|c|c|c|c|c|c|c|c|c|}
\hline \multirow{3}{*}{ Cultivares } & \multicolumn{8}{|c|}{ \% de podridão parda em diferentes datas de coleta } \\
\hline & \multicolumn{2}{|c|}{ 24/out } & \multicolumn{2}{|c|}{$14 /$ nov } & \multicolumn{2}{|c|}{ 24/nov } & \multicolumn{2}{|c|}{ 04/dez } \\
\hline & AHP & $\mathrm{AH}$ & AHP & $\mathrm{AH}$ & AHP & $\mathrm{AH}$ & AHP & $\mathrm{AH}$ \\
\hline A Reubennel & 66,6 & 0,0 & 33,3 & 0,0 & 73,3 & 0,0 & 66,6 & 0,0 \\
\hline A Amarelinha & 0,0 & 0,0 & 0,0 & 0,0 & 0,0 & 0,0 & 0,0 & 0,0 \\
\hline A Harry pickstone & - & - & 13,3 & 0,0 & 0,0 & 0,0 & 33,3 & 0,0 \\
\hline N Sunred & 0,0 & 0,0 & - & - & - & - & - & - \\
\hline P BR-3 & 0,0 & 6,6 & 6,6 & 33,3 & 26,6 & 73,3 & - & - \\
\hline P Chimarrita & 0,0 & 0,0 & 0,0 & 13,3 & 13,3 & 66,6 & - & - \\
\hline P Vila Nova & 0,0 & 13,3 & 0,0 & 0,0 & 0,0 & 6,6 & 0,0 & 0,0 \\
\hline P Premier & 0,0 & 0,0 & - & - & - & - & - & - \\
\hline
\end{tabular}




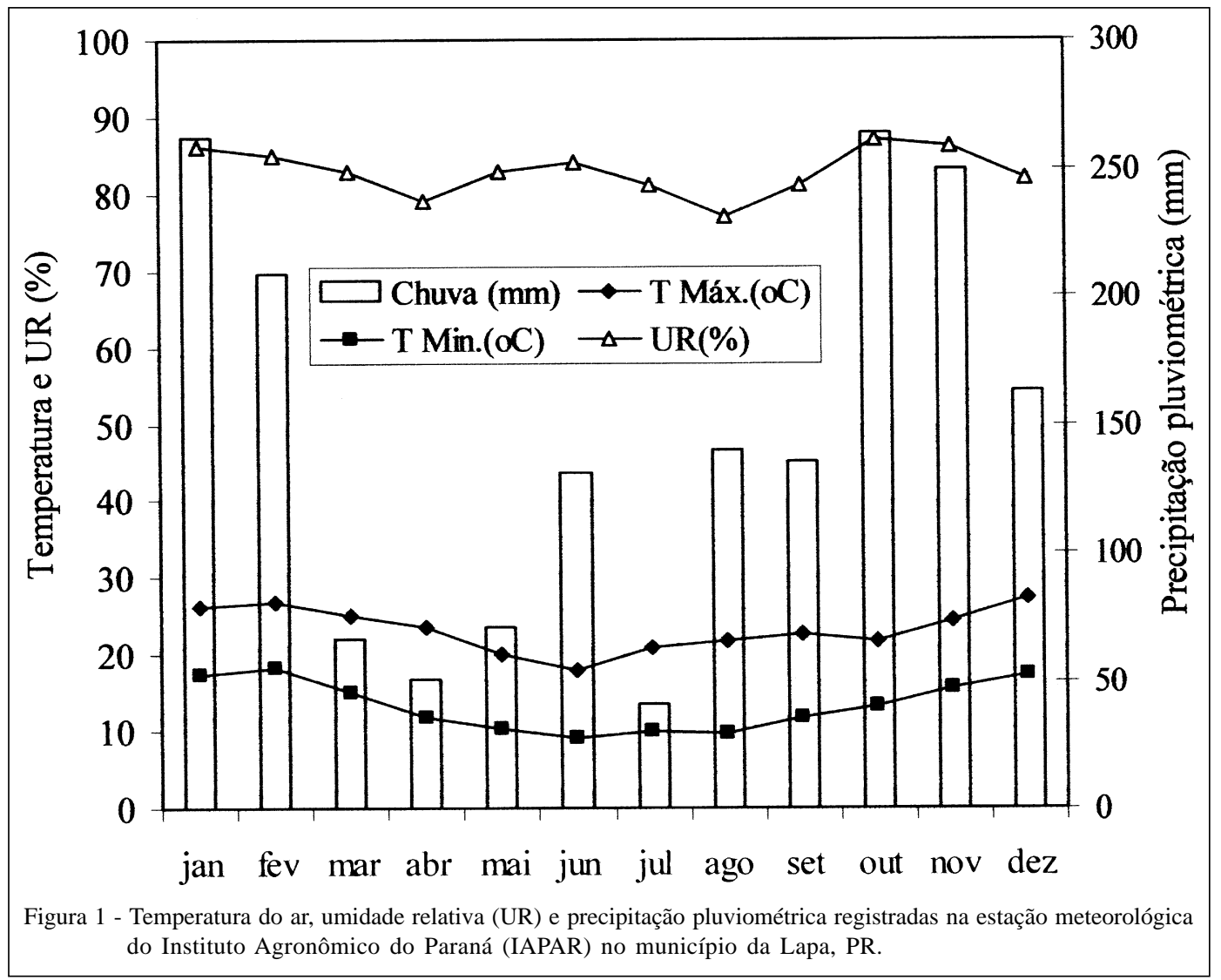

observa-se que a detecção de infecção latente foi mais freqüente com paraquat. Tal observação é explicada por NORTHOVER \& CERKAUSKAS (1994), que relataram que a atividade do herbicida gera radicais livres, os quais induzem a peroxidação de lipídios e a perda da integridade da membrana após a aplicação do produto, facilitando a expressão do sintoma pelo patógeno. No presente trabalho, o uso do herbicida se mostrou mais vantajoso nas cultivares de ameixa do que nas de pêssego, sendo maior a detecção de podridão parda nas cultivares "Reubennel” e "Harry Pickstone" (Tabela 1). Este desempenho também foi observado por NORTHOVER \& CERKAUSKAS (1994) eADASKAVEG et al. (2000), após a imersão de ameixas e cerejas em solução de paraquat. Nos pêssegos, a cultivar "BR-3" exibiu as infecções com os dois métodos de desinfestação durante a maioria das avaliações. Nas cultivares “Chimarrita” e "Vila Nova”, o método sem o herbicida foi mais efetivo (Tabela 1). De modo semelhante, o método de desinfestação com a solução do herbicida foi menos eficaz quando aplicado para pêssego por EMERY et al. (2000).

Outro fato a se considerar na comparação entre os métodos é a ocorrência de modificações no tecido dos frutos, tornando-se mais delgado próximo à fase de maturação. Desse modo, o paraquat não manteve a mesma eficiência que nos frutos verdes, favorecendo inclusive o surgimento de fungos epífitas e/ou contaminantes. Nesta fase, o tratamento feito com etanol e hipoclorito foi mais eficiente e favoreceu as manifestações do patógeno principalmente nas cultivares de pêssego avaliadas (Tabela 1).

Apesar de serem raros os relatos sobre cultivares resistentes e suscetíveis à podridão parda, os resultados obtidos neste trabalho demonstraram a maior suscetibilidade ao patógeno nas cultivares de ameixa "Reubennel” e “H.P.”, e nos pêssegos “BR-3” e "Chimarrita”, em relação às demais testadas, destacando-se a necessidade de se investigar, com mais rigor, estes comportamentos. Em virtude disso, os testes realizados no presente trabalho podem ser utilizados para a obtenção de informações sobre uma possível interferência da anatomia floral, das diferentes cultivares, no favorecimento ou não às infecções, uma vez que as flores constituem uma importante porta de entrada para o patógeno.

A detecção precoce é uma ferramenta importante para o manejo da doença, fornecendo

Ciência Rural, v.37, n.3, mai-jun, 2007. 


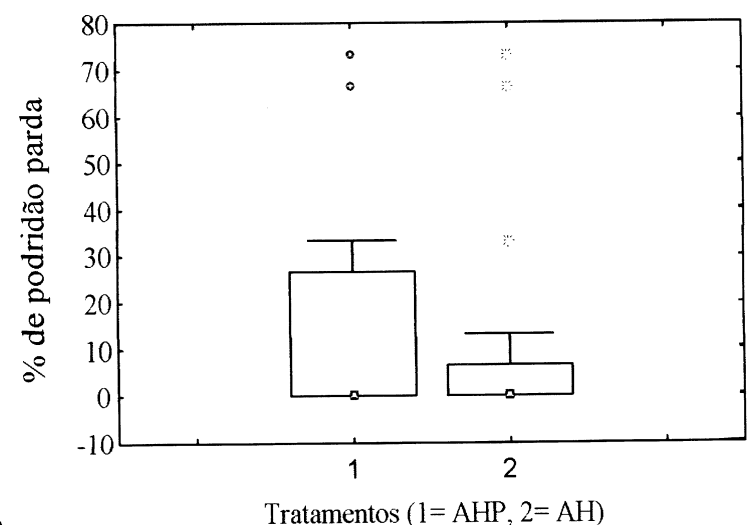

(a)

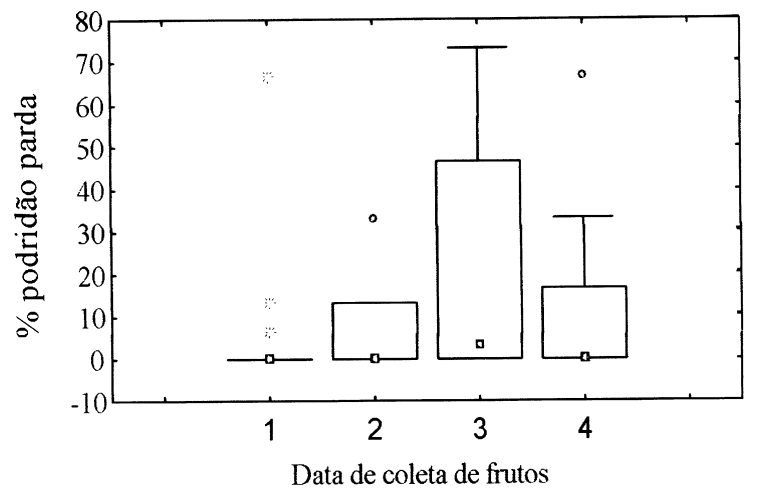

$(1=24 /$ out, $2=14 /$ nov, $3=24 /$ nov, $4=4 / \mathrm{dez})$

(b)

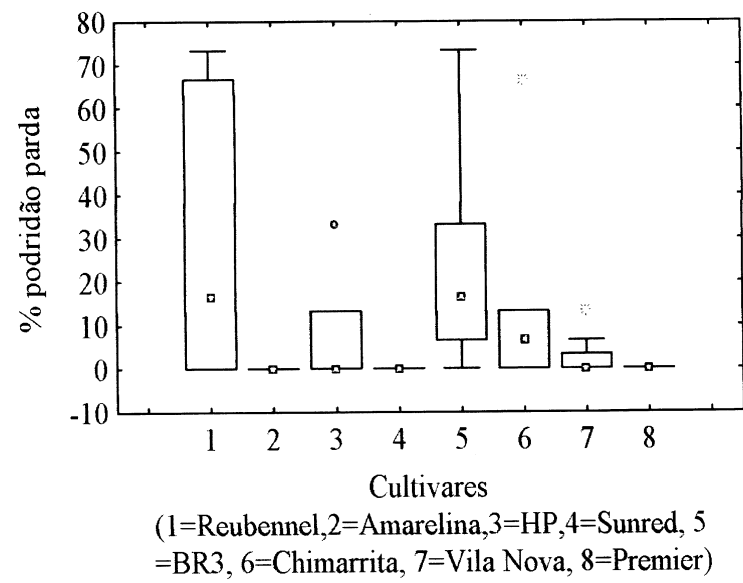

(c)

Média $\square \quad 25-75 \%{ }^{I} \quad$ Desvio padrão ${ }^{\circ}$ Pontos fora do padrão dos dados ${ }^{\circ}$ Dados extremos

Figura 2 - Porcentagem de podridão parda em dois métodos de detecção de infecção latente em frutos de rosáceas de caroço em desenvolvimento (1=Álcool, Hipoclorito, Paraquat; 2=Álcool, Hipoclorito) (a), nas diferentes datas de amostragem (b) e por cultivares de pêssego, nectarina e ameixa (c). Lapa, PR.

subsídios para a elaboração e o acompanhamento da eficácia dos tratamentos de um programa de controle do patógeno. Assim, o monitoramento das cultivares poderia ser utilizado nas propriedades comerciais, estabelecendose um número de amostragens de frutos, de modo que não fossem retirados por um período prolongado, ou então 
utilizando-se para o teste frutos que fossem descartados por ocasião do desbaste, normalmente feito nos pomares comerciais. Deste modo, poderiam ser avaliadas todas as cultivares que compusessem o pomar da propriedade.

\section{CONCLUSÕES}

O monitoramento das infecções latentes durante o ciclo da cultura é eficiente para diagnosticar a presença do fungo $\boldsymbol{M}$. fructicola nos estágios mais precoces de maturação dos frutos. O método de imersão de frutos em paraquat é adequado para cultivares de ameixa, enquanto, para pêssegos, o melhor método é a imersão de frutos em solução de etanol e, posteriormente, em hipoclorito.

\section{REFERÊNCIAS}

ADASKAVEG, J.E. et al. Identification and etiology of visible quiescent infections of Monilinia fructicola and Botrytis cinerea in sweet cherry fruit. Plant Disease, St. Paul, v.84, n.3, p.328-333, 2000

BIASI , L.A. et al. Cultivares de fruteiras de caroço. In: MONTEIRO, L.B. et al. (Ed). Fruteiras de caroço: uma visão ecológica. Curitiba: UFPR, 2004. Cap.2, p.5-32.

BYRDE, R.J.W.; WILLETTS, H.J. Infection. In: The brown rot of fruit: their biology and control. Oxford: Pergamon, 1977. Cap.7, p.87-110.

CRUICKSHANK, R.H.; WADE, G.C. The activation of latent infections of Monilinia fructicola on apricots by volatiles from the ripening fruit. Journal Phytopathology, Berlin, v.136 n.2, p.107-112, 1992.
EMERY, K.M. et al. Incidence of latent infection of immature peach fruit by Monilinia fructicola and relationship to brown rot in Georgia. Plant Disease, St. Paul, v.84, n.8, p.853-857, 2000 .

LUO, Y. et al. Analysis of factors affecting latent infection and sporulation of Monilinia fructicola on prune fruit. Plant Disease, St. Paul, v.85, n.9, p.999-1003, 2001.

LUO, Y.; MICHAILIDES, T.J. Threshold conditions that lead latent infection to prune fruit rot caused by Monilinia fructicola. Phytopathology, St. Paul, v.93, n.1, p.102-111, 2003.

MARI et al. Susceptibility of apricot and peach fruit to Monilinia laxa during phonological stages. Postharvest Biology and Technology, Oxford, v.30, p.105-109, 2003.

MAY-DE MIO, L.L. et al. Doenças de fruteiras de caroço. In: MONTEIRO, L.B. et al. (Ed). Fruteiras de caroço: uma visão ecológica. Curitiba: UFPR, 2004. Cap.10, p.169-221.

MOREIRA, L.M. Alternativas de controle integrado da podridão parda do pessegueiro. 2005. 113f. Tese (Doutorado em Produção Vegetal) - Programa de Pós-graduação em Agronomia, Universidade Federal do Paraná.

NORTHOVER, J.; CERKAUSKAS, R.F. Detection and significance of symptomLess latent infections of Monilinia fructicola in plums. Canadian Journal of Plant Pathology, Ottawa, v.16, n.1, p.30-36, 1994

WADE, G.C.; CRUICKSHANK, R.H. The establishment and structure of latent infections with Monilinia fructicola on apricots. Journal Phytopathology, Berlin, v.136, n.2, p.96106, 1992.

WITTIG, H.P.P. et al. Effect of epiphytic fungi on brown rot blossom blight and latent infections in sweet cherry. Plant Disease, St. Paul, v.81, n.4, p.383-387, 1997. 